Article

\title{
An Approach to Health and Safety Assessment in Industrial Parks
}

\author{
Fco. Javier García-Gómez *, Cristina González-Gaya $@$ and Víctor Fco. Rosales-Prieto
}

Department of Construction and Manufacturing Engineering, National Distance Education University (UNED), C/Juan del Rosal 12, 28040 Madrid, Spain; cggaya@ind.uned.es (C.G.-G.); victor.rosales@ind.uned.es (V.F.R.-P.)

* Correspondence: fgarcia623@alumno.uned.es; Tel.: +34-691850029

Received: 4 March 2020; Accepted: 28 April 2020; Published: 1 May 2020

\begin{abstract}
Safety is a fundamental aspect to take into account in the design, construction and operation of industrial parks. Therefore, it is important to know how to deal with safety in this type of facility, and how to deal with risk analysis. This document provides information related to the industrial park risk assessment process to improve the health and safety of workers in these places. A search and consultation of references related to occupational health and safety management systems is carried out, and it is found that, although there is adequate protection, both in relation to the safety of workers in industrial parks and the safety of personnel outside the facilities, it is helpful to establish a health and safety risk assessment to identify hazards and hazardous events, evaluate associated risks, and select techniques or strategies (opportunities) to manage those risks after prioritization. Following the implementation of the selected techniques, their effectiveness can then be monitored in order to avoid incidents. This document can be a model for future implementation of a health and safety management system based in ISO 45001:2018.
\end{abstract}

Keywords: industrial park; risk assessment; occupational health and safety; safety management; ISO 45001

\section{Introduction}

An industrial park can be defined [1] as a special area that is purposely designed to facilitate a lot of factories, business and offices, and is usually situated on the edge of a town.

The main activities [1] are those related to industrial processes, that is, the operations and infrastructures that allow for the obtaining, transforming, processing and moving of different products. These activities can be related to each other, sharing basic infrastructure and equipment, and common services such as electric power, gas and water. They can also have other common services such as surveillance or access control.

The main differences of industrial parks when compared with other single operating units are usually advantages related improving efficiency and optimizing resources [2]. A major advantage of industrial parks is that they provide an institutional framework, modern services and a physical infrastructure, which are qualities that are rarely seen single operational units. Other differences are determined by their impact on nearby cities [3], and there are also disadvantages, such as increased complexity in responding to emergencies or risk management. Therefore, a health and safety assessment is considered convenient to minimize this disadvantage.

According to the health and safety policies [4] adopted in industrial parks for the prevention of incidents and occupational diseases of its workers and involved third parties, a health and safety (HS) risk management $[5,6]$ process should be established to define the following: 
- hazard identification and analysis approach,

- risk evaluation methodology,

- preventive and protective measures,

- chain of authority and responsibility, and

- monitoring and follow-up.

The assessment process must be performed for activities carried out by industrial park employees on assets or premises directly owned or managed by an industrial park manager. In all other cases, risk management should be carried out through a coordinated effort with the service companies to manage interferences and handovers occurring in the "complex activities" condition.

Parallel to risk management, opportunities are also evaluated for the continuous improvement of the health and safety unit (HS) performance, as offered by changes in work organization, improvement in working conditions and new technology releases.

As such, the HS risk management [5,6] consists of the following steps: identifying hazards and hazardous events, evaluating associated risks, prioritizing risks, selecting techniques or strategies (opportunities) to manage the risks, implementing the selected techniques, and finally monitoring their effectiveness in order to avoid incidents.

This policy defines objectives, criteria and methods for a structured approach to health and safety risk assessment $[5,6]$, and identifies control measures in relation to all potential scenarios that are harmful to the safety and health of workers in their working place and conditions.

Usually, international standards [7-10] and national laws [11-19] already define both risk assessment methodologies and acceptance risk level criteria. However, this policy will contribute to the continuous improvement process of risk minimization, even beyond law provisions, aiming at a continuous risk reduction at values as low as reasonably practicable, according to the industrial parks safety policy [4].

For risk evaluation, we can use the safety-related parts of the methodology for fire strategies in process industry plants [20] in a simplified way.

The HS function of any industrial park should supervise the overall process of HS risk management on behalf of the employer [5,6], providing a harmonization of approaches, maintenance of documents and a continuous process improvement [7].

Industries within an industrial park perimeter should adopt procedures and additional specifications to tailor the methodology to their specific and local technological and organizational features when implementing the present policy.

All risk metrics reported in this policy are exemplary and for reference purpose. Industries might adopt different score levels and thresholds from those described below, provided that the overall approach and the minimum requirements described by this policy are fulfilled.

This policy should be implemented and applied to the greatest possible extent within the industrial park's perimeter and in compliance with any applicable national laws, regulations and governance rules, which in any case prevail over the provisions contained in this document.

\section{Methods}

\subsection{Definitions and Acronyms}

The European Framework Directive (Directive 89/391 EEC) [8] on safety and health at work was the beginning in order to guarantee minimum safety and health requirements throughout Europe, allowing member states to keep or establish stricter measures. Other directives, standards and guidelines have been issued in different matters, such as exposure to chemical agents and chemical safety (f.e. REACH [9]), exposure to physical hazards, exposure to biological agents, or sector specific and worker related provisions.

These, as well as other standards of internationally recognized prestige, such as the Seveso [10] directive, will be taken as a reference. This directive was adopted taking into account, amongst others, 
the changes in the European Union legislation on the classification of chemicals and increased rights for citizens to access information and justice. In addition, current Spanish regulations related to the prevention of occupational hazards, such as Law 31/1995 [13] and Law 54/2003 [14], will be taken into consideration, as well as those relating to safety and health in workplaces such as RD 486/1997 [15] and in works such as RD 1627/1997 [16], those relating to subcontracting as Law 32/2006 [17], those relating to the coordination of business activities such as RD 171/2004 [18], and the evaluation of occupational risks taking data from the INSHT [19].

The international reference standard for risk management, UNE-ISO 31,000 [11], will also be taken into account, which provides general guidelines for risk management, including risk identification, analysis and subsequent evaluation. The UNE-EN 31,010 [12] standard will also be considered as it presents various techniques and provides guidelines for the selection of them and is the system that must be followed to prepare risk studies.

From the information available in the regulations above, we can determine the basis for developing a health and safety assessment in industrial parks and extract acronym and keywords, as presented in Table 1.

Table 1. Acronyms and Keywords.

\begin{tabular}{|c|c|}
\hline Acronyms and Keywords & Description \\
\hline Acceptable Risk & $\begin{array}{l}\text { Risk reduced to a level that can be accepted by the organization with respect to the obligations of } \\
\text { law and the content of this policy. }\end{array}$ \\
\hline Aggregated Risk Value & Combination of risk values evaluated for all hazards, into an overall risk measure. \\
\hline Asset & $\begin{array}{l}\text { Any workplace, construction site or object, which the industrial park owns, manages, operates } \\
\text { or installs, directly or through contractors and subcontractors. }\end{array}$ \\
\hline Continuous Improvement & $\begin{array}{l}\text { Any activity or process aimed at continuous enhancement of installation performance in relation } \\
\text { to HS. }\end{array}$ \\
\hline Critical event & $\begin{array}{l}\text { An event related to a specific hazard occurring in an asset or as consequence of an activity with } \\
\text { the potential to significantly affect the safety of workers and the public. }\end{array}$ \\
\hline Employer & $\begin{array}{l}\text { Industrial park manager that has the responsibility, defined by the local law and/or by the } \\
\text { company organization, to ensure the health and safety of the people working for the company. }\end{array}$ \\
\hline Hazard & $\begin{array}{l}\text { Source or situation that may cause harm or adverse health effects to people, such as an injury, an } \\
\text { occupational disease or a combination of these. }\end{array}$ \\
\hline HS & $\begin{array}{l}\text { Health and safety unit, or internal to the operating and organizational units. They are the } \\
\text { industrial park workers within the HS unit, system and external or internal positions in which } \\
\text { they aim to prevent-and protect people from-occupational hazards. }\end{array}$ \\
\hline Impact Magnitude & Outcome of the critical event, measured as relevance by its qualitative and quantitative effects. \\
\hline Indicator & $\begin{array}{l}\text { Measurable representation of the condition, status or variation of a system (e.g., process, activity, } \\
\text { phenomenon, sample). }\end{array}$ \\
\hline Inherent Risk & Risk present in absence of existing control activities. \\
\hline Likelihood & Probability of occurrence of the critical event in a specific exposure period. \\
\hline Magnitude & $\begin{array}{l}\text { Potential effect caused by exposure to work-related risk; for example, the noise agent of risk can } \\
\text { cause a reduction in the hearing threshold, i.e., the onset of hearing loss (damage) }\end{array}$ \\
\hline Organizational Unit (OU) & $\begin{array}{l}\text { Minimal part of the industrial park with direct responsibility of its workers' safety and that is } \\
\text { able to develop a risk assessment. }\end{array}$ \\
\hline PPE & Personal protective equipment. \\
\hline Risk & $\begin{array}{l}\text { Combination of the likelihood of an occurrence of a critical (hazardous) event or exposure(s) and } \\
\text { the severity of injury or ill health that can be caused by the event or exposure(s). }\end{array}$ \\
\hline Risk Assessment & Overall process of estimating the level of risk and deciding whether the risk is acceptable or not. \\
\hline Risk Control & $\begin{array}{l}\text { Any action of guidance, operation or influence taken to directly or indirectly reduce a } \\
\text { risk.(Passive measures (barriers) and active measures (safety systems, procedures, etc.) are } \\
\text { considered part of control measures.) }\end{array}$ \\
\hline
\end{tabular}




\subsection{Health and Safety Risk Management Process}

The international standards [11,12] already indicates different techniques, widely used in large industrial facilities, to be taken into account for risk analysis, such as hazard and operability (HAZOP), fire hazard analysis (FHA), safety integrity level (SIL), safety requirement specifications (SRS), quantitative risk assessment (QRA), failure mode effects analysis (FMEA), and others [21-24].

The experience of the HS unit in the different techniques mentioned above will allow for the optimization of the development of the health and safety assessment to be applied in each industrial park.

Each organizational unit within an industrial park perimeter should perform a risk assessment in coordination with its referent HS Unit at any level of its organization. This process aims at highlighting the hazards and therefore the most relevant risks people are exposed to, and at identifying the efforts to eliminate or reduce risk levels in order to control them until the agreed acceptance thresholds are reached.

Both the results of the assessment and the methodology being used should be described in the risk assessment document, which should be regularly maintained, updated, and communicated to all interested parties.

In relation to all potential harmful scenarios to the safety and health of workers in their working place (or activity), the document will describe the main steps of the assessment process presented in Figure 1 and are listed below.

1. Activity planning: this is the "scope" of risk assessment (e.g., what, how, who, when).

2. Hazard identification: all potential hazards should be identified and outlined (sources, situations or acts that may cause harm to workers).

3. Consequence evaluation: the potential impacts and harmful consequences to workers should be then calculated in terms of likelihood and magnitude (qualitative judgement).

4. Risk assessment: this determines the level of risk exposure from each identified hazard on the concerned target. Usually it is a combination of the likelihood and the severity of occurrence (e.g., injuries or ill health issues caused by the event itself).

5. Risk control: risk level should be reduced as low as reasonably practicable to an agreed acceptable level. Suitable mitigation measures should be designed and their effectiveness in risk reduction should be further assessed. Risk assessment must be repeated in case controls fail to prevent incidents, effects are not mitigated as expected, or operational conditions change.

6. Long term risk control: the development of a remedial plan to be implemented and monitored over time at the site or installation site is also expected. 


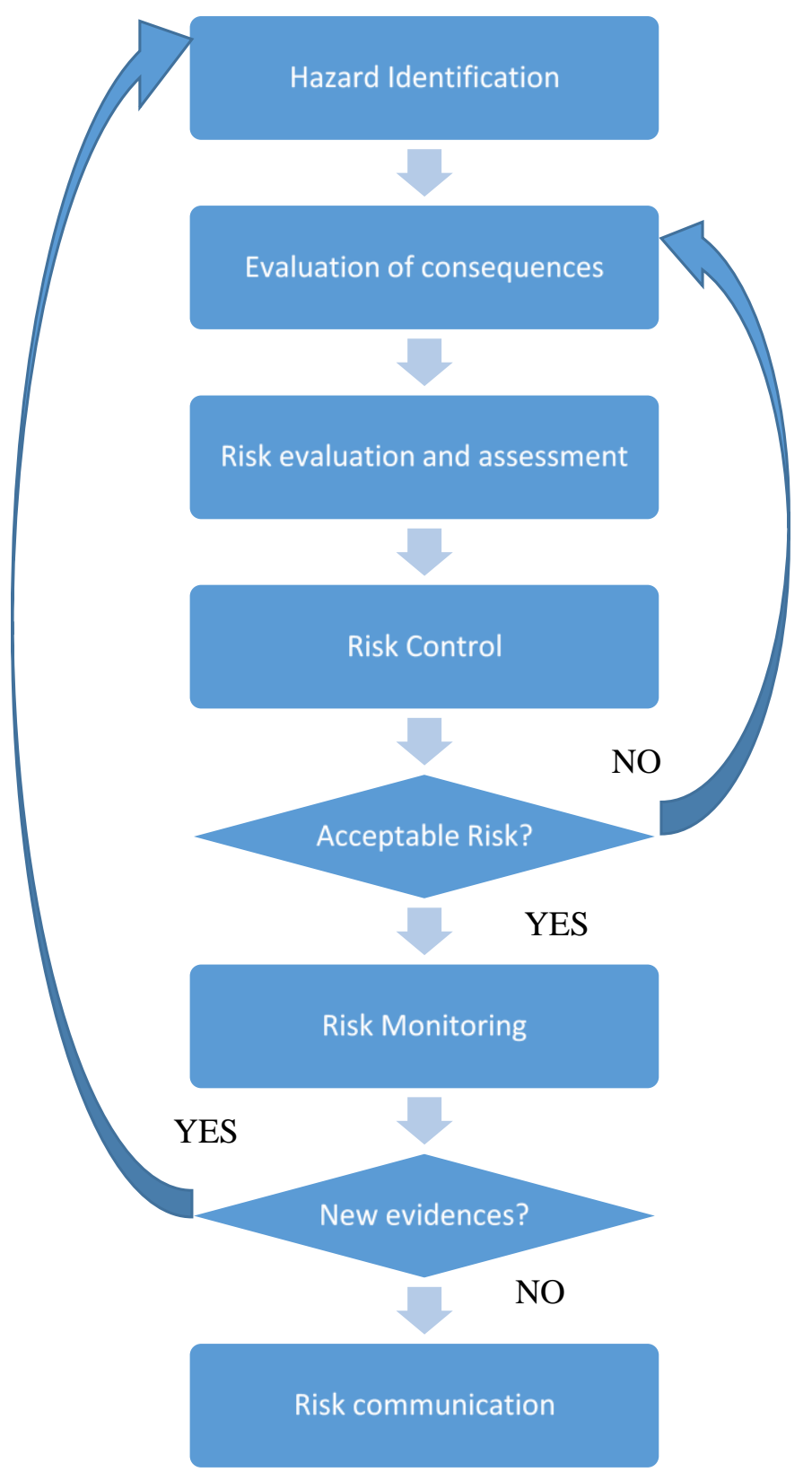

Figure 1. Reference sequence for risk management.

\section{Results}

\subsection{Activity Planning}

The first step will be to make good planning to identify potential problems, analyze how likely they are to occur, take action to prevent the risks that can be avoided, and minimize those that cannot be solved.

For the work planning, a specialist from the HS unit should be trained in the reduction or minimization of risks of interferences of different activities in industrial parks.

The specialist from HS unit called to cover the role of coordination and control in the planning phase should have the following features:

- qualification risk analysis and assessment of possible interferences in activities,

- qualification in the identification of prevention and protection measures against the risks-especially those related to interference among the realization of different activities, 
- knowledge of the safety regulations and standards (national and international),

- $\quad$ ability of coordination and mediation between different needs and profiles, and

- skills of responsibility and leadership in also dealing with special situations.

The risk assessment should be planned for deciding how to approach and conduct the risk management activities. Namely it is the "plan" to perform the risk management task, and at a minimum these areas are developed as follows:

- $\quad$ project scope and expectation;

- identified inputs: work activities, working areas, safety records, legal requirements and other business constrains;

- company safety, environmental and quality standards and regulations;

- legal provisions and country legislation; and

- organizational process or objectives to manage assets.

As result, the planning outputs should be as follows:

1. methodology approach,

2. definition of roles and responsibilities,

3. budgeting allocation,

4. timing and milestones,

5. identification of risk categories,

6. residual risk acceptance criteria,

7. reporting format (risk register or risk assessment report),

8. implementation tracking and efficiency estimation of prevention measures, and

9. risk assessment updating.

\subsection{Hazard Identification}

Risk management starts with the gathering and analysis of information on work activities and workplace hazards from both direct and indirect sources (e.g., interferences).

The first step of the hazard identification [11,12] is the clear identification of the assessed target(s): how the analysis should be performed and what will be assessed. It could be an asset (power plant, primary substation, office ... ), a company business, a working site, a single product or a cluster in relation with the activity that is considered.

Furthermore, all the "primary" tasks that form the work activities should be also identified. For example, the execution of an installation usually includes at least the following steps: excavation and road works; electrical connections; mechanical coupling. In contrast, maintenance activities on a power grid should consider disconnection from the grid; dismantling, replacement and assembly; and reconnection and testing. The grade of the activity breakdown depends on how accurate and detailed the analysis needs to be, or on the complexity of the works.

It is therefore necessary to conduct an inventory of HS hazards that can potentially occur for each activity and subactivity.

For example, there is a list of possible HS hazards to consider presented below:

List of Hazards

The following nonexclusive list of hazard categories that should be investigated may be used for completeness check:

- Job related hazards $[13,16]$, mainly related to construction, operation, and maintenance job conduct, such as

- $\quad$ hazards induced by vehicles (use of or interference with);

- $\quad$ hazards induced by working equipment, tools and lifting devices; 
- $\quad$ slip, trip, and fall hazards;

- $\quad$ hazards induced by falling and moving objects (could also be passive, not job related);

- $\quad$ electrical hazards (could also be passive, not job related); and

- $\quad$ hazards from defective equipment maintenance and calibration.

- Facility process induced hazards [13,15], mainly area hazards, which could be generated in the overall working environment (and also site vicinity), and not necessarily related to the job conduct, such as

- $\quad$ hazards from fire and explosion (pressure wave, heat, burning and projectiles);

- $\quad$ hazards from operation of equipment other than those directly involved in the job;

- $\quad$ chemical hazards, including general air quality;

- $\quad$ physical hazards (noise, dust, heat, radiation, vibration, electrical field, etc.);

- biological hazards (bacteria, viruses, fungi, other microorganisms and their associated toxins);

- natural hazards induced by site external events, or external to the working place (earthquakes, flood, wind, high and low extreme temperature, wet environment, spill of hazardous materials, structural collapse, etc.); and

- $\quad$ hazards associated to ergonomic risk factors, working conditions (difficult access, poor lighting, heavy lifting, repetitive actions, etc.).

- Human behavior induced hazards $[13,17]$, such as

- $\quad$ hazards induced by willful psychological behaviors (willful acts, etc.); and

- $\quad$ omission errors (lack of protective devices, deliberate wrong maneuvers, etc.).

- Organizational hazards $[13,18]$, such as

- hazards induced by work organization and work process flow (including supervision, leadership, staffing, interferences and scheduling);

- $\quad$ hazards induced by (wrong) work practices and procedures; and

- $\quad$ hazards associated with emergency situations and nonroutine tasks

The analysis of each hazard type should be carried out with different approaches in relation to the nature of the hazard itself, the complexity of the works being performed and the potential harmful effects or impacts:

- Hazard analysis of area sources $[13,15]$ (typical for process related hazards), within each subarea if the working area is divided into several parts (hazards present in the working area-subarea independently of tasks carried out). A hazard analysis is typically made identifying all stationary sources generating chemical, physical, fire, collapse, etc.

- Job hazard analysis [13,16,17] (typical for job related and organizational hazards) for each task performed (hazards that depend only on activities, regardless of the area conditions). The job-related hazard analysis should be focused on the relationship between the worker, the task, the tools, and the work environment. Typically, this analysis can be used as a way to identify hazards before they occur.

- Human behavior and organizational $[13,18]$ analysis (typical for human behavior and health hazards). Special techniques of data collection on human attitude and behavior should be applied, with reference to suitable models. Data collection is typically managed through checklists, and behaviors are assessed against reference models.

In particular the experts in performing the assessment should carry out the following actions in order to collect the necessary data: 
1. Identify activities performed in the unit or perimeter and break them down into elementary tasks.

2. Collect and review information about the hazards present or likely to be present in the workplace which are due to the job performed or external sources.

3. Conduct workplace inspections (at all working areas in all working conditions and statuses, site vicinity, warehouses, storages, offices, electrical areas, etc.) to identify new or recurring hazards. Additional inspections can be conducted on a regular basis to update the hazard identification, since hazards could be introduced over time as workstations and processes change.

4. Investigate records and trends from injuries, illnesses, incidents, near misses and nonconformities, to review their causes and determine the underlying hazards.

Standard categories which might form the basis for inventories include

- a description of the locations which each manager is responsible for, including, if appropriate, a sketch map;

- $\quad$ a register of the employees regularly present at the locations (task and role);

- a register of people who may enter hazardous areas such as visitors and contractors;

- a list of the permanent or semipermanent items of machinery and equipment usually present at location;

- a list of power tools and other devices used at location;

- a list of the hazardous chemicals and substances stored, transported or used at location;

- a list of the main energy sources, such as electricity, LPG and radiation, used at location;

- a list of the tasks carried out at location; and

- an analysis of human factors (organizational and behavioral).

The most advisable approach to identify hazards is visiting assessment targets to check assets, premises, working areas and the specific activities that are taking place. Personnel exposure to unsafe conditions such as proximity with HV/MV electrical equipment, handling of harmful materials, and working at height in adverse environment should also be considered. Furthermore, for a more effective hazard identification process, this task must be completed with observation of the way people work with the objective of identifying unsafe acts or behaviors.

Although direct witness is the most powerful method of hazard identification, it must be carried out by personnel with the appropriate experience and it must be a creative process. Passive observation must therefore be supplemented with queries about the job performed and surrounding working environment etc.

Safety and health specialists should consult managers and workers in order to gather the best experience and historical memory. It is imperative that the relevant staff are involved throughout the study to ensure that the right assumptions are made and are correctly used.

The hazard identification analysis should be periodically repeated, particularly in case original working conditions change due to one or a combination of the following:

- $\quad$ significant events that occurred in the industrial park;

- evidence from medical surveillance;

- new solutions for mitigation and prevention made available by developments in innovation technology;

- changes in work organization (restructuring, changes in management policies, working methods, etc.);

- physical changes in the installation due to ageing, environmental and configuration changes, interferences with new installations, etc.;

- a need for maintenance of monitoring, alerting, alarms connected to hazardous scenarios; and

- changes in local regulations, international standards or industrial park policies. 


\subsection{Evaluation of Harmful Consequences to Workers}

After hazard identification, the specialists of each organizational unit supervised by HS specialists should assess the consequences $[11,12,19]$ of worker's exposure to such hazards with reference to

- personal safety: injuries, physical harms or impacts; and

- personal health: occupational disease, work related psychological diseases and wellness conditions.

Risk level exposure should then be calculated by means of the combination of two elements, as determined for the occurrence of the associated worst-case scenario:

- $\quad$ magnitude of consequence (Mc); and

- likelihood of event occurrence (Le)

When detecting for impacts or consequences related to any relevant hazard, the system condition under which a hazard might occur should be considered amongst the following activity conditions:

- normal condition (planned activities under standard running conditions);

- abnormal condition (planned activities under transient and extraordinary running conditions (this category might eventually be included in the previous one if common control procedures and levels are present)); and

- $\quad$ emergency condition (unexpected occurrences causing one or more safety relevant event(s)).

This policy is based on the risk screening matrix [11,12,19] approach, which is deemed more effective for HS applications in the energy field. However, an evaluation of the most reliable tool should be carried out by the analysts in order to choose the most appropriate ones.

\subsubsection{Likelihood}

After identification of the hazard scenarios and sources, their likelihood should be evaluated and categorized according to criteria detailed in Table 2.

Table 2. Likelihood Value.

\begin{tabular}{|c|c|c|}
\hline Value & Level of Likelihood & Criteria \\
\hline 1 & Very Unlikely & $\begin{array}{l}\text { - There are unknown events that already occurred in similar contexts in the } \\
\text { technical literature. } \\
\text { - The occurrence of the event would be considered highly improbable. } \\
\text { - Unlikely and unrelated impacts can follow the event. }\end{array}$ \\
\hline 2 & Unlikely & $\begin{array}{l}\text { - } \quad \text { Only very rare events have been reported. } \\
\text { - } \quad \text { The occurrence of the event would be considered almost improbable. } \\
\text { - Only in the case of adverse conditions or impacts can the event follow. }\end{array}$ \\
\hline 3 & Likely & $\begin{array}{l}\text { - } \quad \text { Few events recorded in technical literature or in our group, in similar contexts. } \\
\text { - The occurrence of the event would be considered probable. } \\
\text { - The event can generate impacts even if not in an automatic or direct way. }\end{array}$ \\
\hline 4 & Very Likely & $\begin{array}{l}\text { - Several events occurred and recorded in technical literature or in our group, } \\
\text { in similar contexts. } \\
\text { - The occurrence of the event is possible. } \\
\text { - There is a direct correlation between the event and the impact occurrence. }\end{array}$ \\
\hline
\end{tabular}

The proposed scale of values is definitely qualitative and subjected to assessors' judgement.

In order to provide a generic quantitative reference for a parametrization of the whole scale, as shown in the table above, it can be noted that scientific literature associates a recurrence probability of 10/year to level 4 above, up to 10-3/year to level 1 above. 


\subsubsection{Magnitude}

Any metric of magnitude of health and safety consequences should consider both the fatality and severity of the induced injuries to human beings, and number of workers potentially involved. A common metric for incident severity is associated to the number of days of the associated medical prognosis rather than other parameters, such as indemnification costs, insurance costs or business interruptions costs. The most suitable metric can be chosen at the organizational unit and should be thoroughly documented.

It's worth pointing out that the evaluation of the magnitude from a specified source should consider the spreading of the effects from the source to the likely impacted environment. Therefore, any time a hazard generates effects that might be correlated (domino effect), the cumulative impact should be considered with a detailed analysis of the duration of the source emission, propagation (speed and time) means and path barriers, and the effect scenario on impacted workers.

A proposal for magnitude quantification is shown in Table 3. It should refer to the worst consequence from any identified source if effects are uncorrelated. In the case that they are correlated, the cumulative effect should be evaluated, and the worst-case scenario taken into account.

Table 3. Impact Magnitude.

\begin{tabular}{|c|c|c|}
\hline Value & Magnitude & Criteria \\
\hline 1 & Minor & $\begin{array}{l}\text { - Not known to have happened, or isolated cases worldwide, with prognosis } \\
\text { on potentially affected workers } \leq 1 \text { day. } \\
\text { - Limited and restricted impacts on workers or assets. }\end{array}$ \\
\hline 2 & Moderate & $\begin{array}{l}\text { - Known events rarely occurred in the last three years with prognosis on } \\
\text { affected workers lasting up to } 3 \text { days. } \\
\text { - } \quad \text { Moderate but restricted impacts on workers or assets. }\end{array}$ \\
\hline 3 & Significant & $\begin{array}{l}\text { - Known to have happened in last years, with consequences on potentially } \\
\text { affected workers lasting between } 3 \text { and } 30 \text { days of prognosis. } \\
\text { - Important business interruption to restore safe working conditions. }\end{array}$ \\
\hline 4 & Severe & $\begin{array}{l}\text { - Known to have happened in recent years, with consequences on potentially } \\
\text { affected workers in the range of more than } 30 \text { days of prognosis, permanent } \\
\text { disability, or fatality. } \\
\text { - } \quad \text { High widespread impacts on workers. } \\
\text { - Prolonged business interruption to restore safe working conditions. }\end{array}$ \\
\hline
\end{tabular}

\subsection{Risk Evaluation}

For those identified hazards, the inherent risk should then be calculated as follows: subsequently, risks from all hazards should be prioritized and screened out based on suitable acceptance criteria.

$$
\text { Inherent risk }=\text { likelihood of exposure }(\mathrm{LE}) \times \text { magnitude of consequence }(\mathrm{Mc})
$$

In the case of multiple effects from one hazard type, the "worst-case" classification should be assigned.

Finally, risks related to each hazard should be calculated and their relevance should be assigned according to scoring levels in Table 4. 
Table 4. Risk categorization as a function of source likelihood and impact magnitude of consequences.

\begin{tabular}{clllll}
\hline \multirow{2}{*}{ Inherent Risk and Relevance } & \multicolumn{4}{c}{ Impact Magnitude (Mc) } \\
\cline { 3 - 5 } & 1.Very Unlikely & 1.Minor & 2.Moderate & 3.Significant & 4.Severe \\
\hline \multirow{2}{*}{$\begin{array}{l}\text { 2.Unlikely } \\
\text { 3.Likely }\end{array}$} & 2.Marginal & 2.Marginal & 3.Marginal & 4.Marginal \\
\cline { 3 - 5 } & 4.Very Likely & 4.Marginal & 6.Moderate & 9.High & 12.High \\
\cline { 3 - 6 } & 4.Marginal & 8.Moderate & 12.High & 16.Critical \\
\hline
\end{tabular}

The proposed scale of values is definitely qualitative and subjected to expert judgement, following the same approach in the hazard scale. Intermediate values for risk are allowed, based on expert judgement, provided that limits to the risk classes are referred to those in Table 4.

As an alternative to the approach summarized in Table 4, for the hazards (typically health related) when risks (Le $\times \mathrm{Mc}$ ) cannot be explicitly evaluated and the magnitude of consequence is time dependent, the risk can be directly estimated with reference to the acceptable limits, defined in terms of risk value (RVx), according to Table 5 .

Table 5. Risk evaluation according to source threshold values.

\begin{tabular}{cccl}
\hline $\begin{array}{c}\text { Risk Level Induced by } \\
\text { Identified Sources }\end{array}$ & Risk Category & Level of Hazard Source & \multicolumn{1}{c}{ Description } \\
\hline $13-16$ & Critical & Source level $>\mathrm{RV}_{\mathrm{L}}$ & Unacceptable consequences-stop work. \\
\hline $9-12$ & High & $\mathrm{RV}_{\mathrm{L}}>$ Source level $>\mathrm{RV}_{2}$ & $\begin{array}{l}\text { Exposition to source should be limited } \\
\text { in time, source effects should be } \\
\text { monitored, and a risk reduction plan } \\
\text { should be developed in the short term. }\end{array}$ \\
\hline $5-8$ & Moderate & $\mathrm{RV}_{2}>$ Source level $>\mathrm{RV}_{1}$ & $\begin{array}{l}\text { Exposure to source tolerated, provided } \\
\text { source effects are monitored and } \\
\text { limits assessed. }\end{array}$ \\
\hline $1-4$ & Marginal & $\mathrm{RV}_{1}>$ Source level & No significant detectable health effects. \\
\hline
\end{tabular}

\section{Discussion}

\subsection{Assessment of Risk Control Measures}

Once the potential significance of risks has been assessed, proper risk responses must be defined. This activity typically involves judgments based on the desired level of residual risk the organization is willing to manage and a cost-benefit analysis on the internal effort required to achieve it.

Risk responses fall within the following categories:

- acceptance: no action needs to lower the risk likelihood or impact;

- avoidance: exiting the activities that give a rise to risk;

- reduction: action(s) taken to reduce risk likelihood, impact or both, depending on the daily decisions that management is required to take; and

- sharing: reducing risk likelihood or impact by transferring or sharing a portion of it.

In relation to possible risk scenarios, the implementation of feasible mitigation measures should be assessed and, if possible, augmented in order to reduce the risks to acceptable levels as explained below.

All available mitigation measures (physical barriers, segregation, monitoring systems, emergency measures, less harmful materials, govern regulations etc.) must be taken into account in order to evaluate the actual probability of occurrence and the associated consequences. Subsequently, risks should be prioritized and screened out based on agreed acceptance criteria. 
All opportunities for a risk management improvement, offered by changes in work organization, in working environment and health of the workers should be also monitored and addressed by the risk continuous monitoring process.

In general, risk controls are applied in order to reduce risk level to as low as reasonably practicable. This process should be documented in the risk assessment document, where such "opportunities" should be highlighted.

Risk mitigation effort should be developed in relation to each hazardous scenario. Based on risk calculation results, risk acceptance and consequent needs for risk control actions should be defined according to specified criteria as those shown below.

- $\quad$ Marginal $=$ risk value $\leq 4$ :

- no specific action plan is formally required, as long as the hazard scenario and the existing controls remain unchanged.

- $\quad$ Moderate $=$ risk value $\geq 6$ and $\leq 8$ :

- no specific risk reduction plan is formally required, but the effectiveness of the existing controls should be periodically monitored, and ad hoc actions can be implemented in order to meet the "as low as reasonably practicable" approach.

- $\quad$ High $=$ risk value $\geq 9$ and $\leq 12$ :

- a specific risk reduction plan is formally required for the area of concern, with priority to the reduction of the dominant risk contributing to the aggregated value; and

- $\quad$ if not already present, the organizational unit should consider the opportunity to issue a specific operational procedure or technical instruction on risk control.

- $\quad$ Critical $=$ Risk Value $=16$ :

- Apply stop work policy as immediate action. A specific risk reduction plan is formally required for the area of concern before activity restarts.

Different strategies can be followed for risk reduction through mitigation and control, such as

- eliminating or control all high and critical risk levels (hazards that are causing or are likely to cause death, injuries, serious physical harm, illnesses);

- selecting controls according to a hierarchy that emphasizes engineering solutions (including elimination or substitution, intrinsic safety design) first, followed by safe work practices, administrative or managerial controls, collective protective equipment and finally personal protective equipment (PPE); and

- whenever possible, selecting equipment, machinery, and materials that are inherently safe based on the application of "prevention through design" principles.

Other examples to eliminate or reduce job-related types of risk are to

- develop safer ways, procedures and instructions to do the jobs or use less harmful products and materials. Apply changes in work processes;

- address risky human behaviors through communication, commitment, awareness, training, personal protection, surveillance, work organization, procedures;

- enforce changes in equipment and tools types, calibration, etc;

- provide equipment replacement or improved engineering controls: they can eliminate the hazard (e.g., machine guards, improved lighting, better ventilation, etc.);

- add administrative controls, or changes in how the working tasks are done; it can be used if engineering controls are not possible (e.g., rotating jobs, changing the steps, training); and identify changes in personal protective equipment (PPE). 


\subsection{Risk Reduction Plan}

A risk reduction plan is created as part of a risk management process, wherein steps are determined which will address a particular program risk so as to reduce either its likelihood of occurrence, or the consequence of its occurrence, or both, such that there is a reduction in its potential impact to the program.

A risk reduction plan describes how the controls selected for the specific risk reduction should be implemented in time and periodically reassessed to meet the expected objectives. Interim controls may be necessary, but the overall goal is to ensure the effective long-term control of hazards. It is important to track progress toward completing the control plan and periodically (at least annually and when conditions, processes or equipment change) verify that controls remain effective, also as a result of modification on installation, environment and working conditions.

A practical way to implement a risk reduction plan, may be to follow the following steps:

- list the risks needing controls in order of priority,

- define control measures and actions to reduce risks to acceptable shared levels,

- assign responsibility for installing or implementing the controls to a specific person or persons with the power or ability to implement the controls,

- establish a target completion date,

- plan how the HS unit will track progress toward completion, and

- plan how the HS unit will verify the effectiveness of the controls after they are installed or implemented.

Once the action plan is implemented, in order to ensure that control measures are and remain effective, the HS unit should track progress in implementing the controls, inspect and evaluate the controls once they are installed, and follow routine preventive maintenance practices of the control measures themselves.

Continuous monitoring allows one to have a constantly updated view of the evolution of risks and the progress of processes and strategies put in place to avoid and control them. Furthermore, it also allows for the effective implementation of the established risk management mechanisms, including policies, standards and procedures.

\subsection{Training and Communication}

Communication and training programs should be developed to inform workers and managers about workplace hazards, risk assessment outcomes and controls. Furthermore, an adequate communication of the risk assessment will provide workers and managers with a greater understanding of the safety and health program itself, so that they can contribute to its development and implementation.

Education and training provide employers, managers, supervisors, and workers with the following:

- knowledge and skills needed to do their work safely and avoid creating hazards that could place themselves or others at risk;

- awareness and understanding of workplace hazards and how to identify, report, and control them; and

- $\quad$ specialized training, when their work involves unique hazards.

Additional, specific training may be provided depending on the roles assigned to employers or individual managers, supervisors, and workers. For example, employers, managers, and supervisors may need specific training to ensure that they can fulfil their roles in providing leadership, direction, and resources for the safety and health program. Workers assigned specific roles in the program (e.g., incident investigation team members) may need dedicated training to ensure their full participation in those functions. 
In regard to keeping the training of workers up to date, the process presented in the Figure 2 can be proposed.

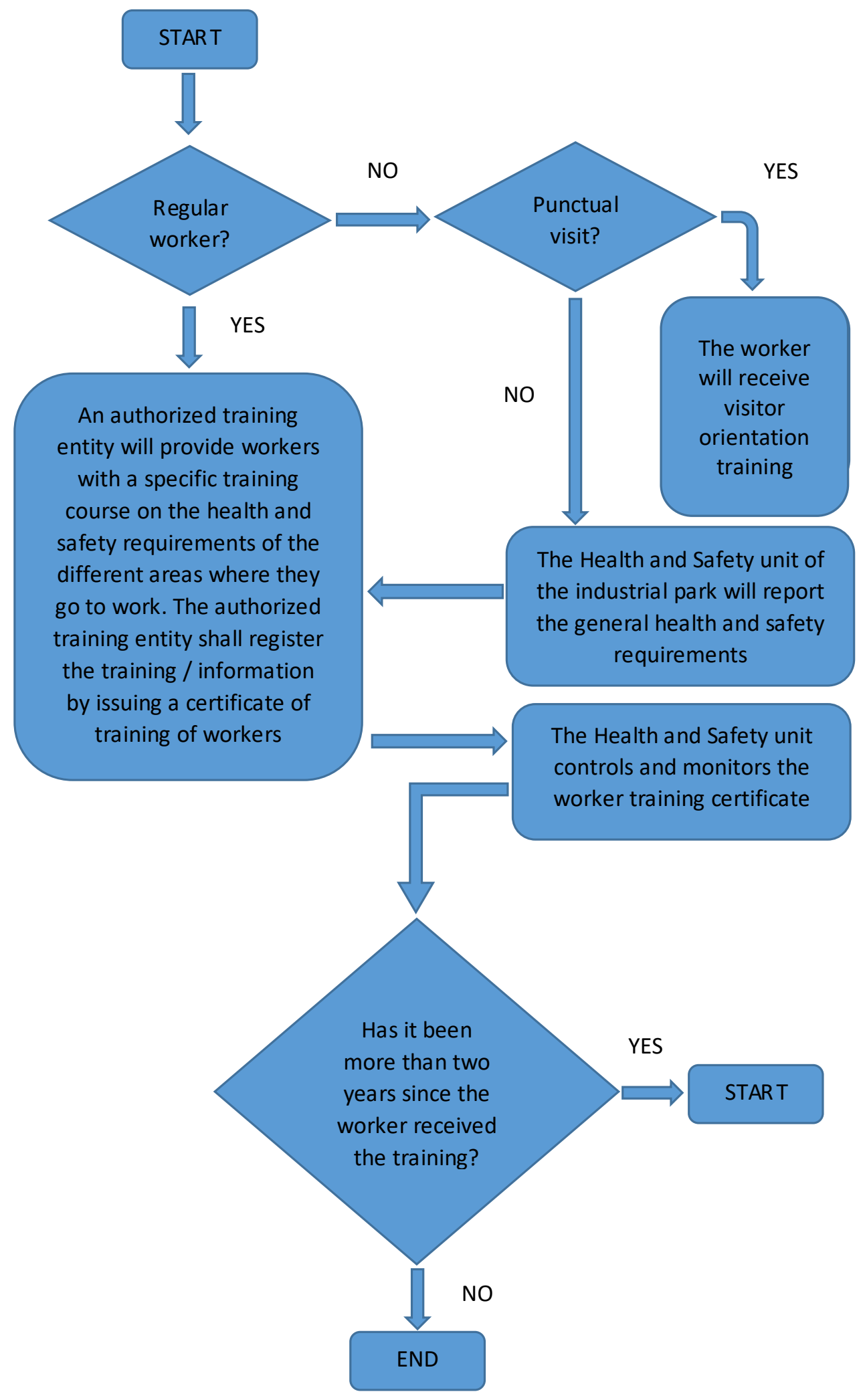

Figure 2. Training process. 


\section{Conclusions}

Health and safety policies have reached high quality standards in industrial parks because the industry has developed technology and operations to ensure the safety of its operations. Although each country has its own regulatory requirements for industrial parks, the sector also benefits from the development of international standards and the policies that regulate the industry.

Establishing an assessment process according to the health and safety policies adopted in industrial parks will improve the safety and health of all plant workers.

The safety and health responsibilities of the main employer require a strong commitment to comply and enforce policies related to the prevention of occupational hazards.

Therefore, it is concluded that the document presented can be a model that allows for the improvement of the safety of the processes and activities of industrial parks, and that starts the path for a future implementation of a health and safety management system based in ISO 45001:2018. In addition, the proposal presented focused on the prevention of occupational and health-related risks, could help the transition from OHSAS 18001 to ISO 45001:2018.

A health and safety assessment is important because it provides a road map for the implementation and improvement of industrial park safety practices. As an industrial park implements its framework, it will be able to articulate goals, evaluate the safety over time, and determine the need for additional measures.

Specifically, an industrial park health and safety assessment is intended to be suitable for the following:

- a way to ensure that safety risks are effectively managed;

- to ensure that the specific safety objectives of an industrial park are met by establishing a process for the implementation and management of controls;

- to define new safety management processes;

- use by a HS unit to determine the status of industrial park safety management activities; and

- use by internal and external auditors to determine the degree of compliance with the policies, directives and standards adopted by the industrial park.

A health and safety assessment must be kept under review in order to ensure that agreed safe working practices continue to be applied, and take account of any new working practices, new machinery or more demanding work targets.

Overall, an industrial park must have a solid base for its safety framework. The risks will change over time; however, if the industrial park continues to follow its framework, it will be in a good position to address any new risks that arise.

Author Contributions: F.J.G.-G.: Conceptualization, methodology, formal analysis, validation, investigation, resources, data curation, writing-original draft preparation, visualization. C.G.-G.: supervision, writing-review and editing, project administration. V.F.R.-P.: validation, writing-review and editing. All authors have read and agreed to the published version of the manuscript.

Funding: This research was funded by the ETSII-Universidad Nacional de Educación a Distancia (UNED) of Spain. Grant number 2020/ICF01.

Acknowledgments: This paper is based on the ongoing research of the lead author's Ph.D. thesis, under preparation at the International Doctorate School of UNED (EIDUNED); the authors therefore wish to express their gratitude for the support from that Institution.

Conflicts of Interest: The authors declare no conflict of interest.

\section{References}

1. Vidová, J. Industrial Parks-History, Present and its Influence to the Employment. Rev. Econ. Perspect. 2010, 10, 41-58. [CrossRef] 
2. Liana-Eugenia, M.; Nicoleta-Georgeta, B. The Role of Industrial Parks in Economic Development. The Annals of the University of Oradea; Faculty of Economics, University of Oradea: Oradea, Romania, 2013. Available online: https://ideas.repec.org/a/ora/journl/v1y2013i1p123-130.html (accessed on 18 April 2020).

3. Ben, T.M.; Wang, K.F. Interaction Analysis among Industrial Parks, Innovation Input, and Urban Production Efficiency. Asian Soc. Sci. 2011, 7, 56. [CrossRef]

4. HSE-Health and Safety Executive. Health and Safety Policy. Available online: www.hse.gov.uk/simplehealth-safety/policy/index.htm (accessed on 19 April 2020).

5. ISO 45001:2018 Occupational Health and Safety Management Systems-Requirements with Guidance for Use. Available online: www.aenor.com/normas-y-libros/buscador-de-normas/iso/?c=063787 (accessed on 19 April 2020).

6. OHSAS 18001:2007. Occupational Health and Safety Management System. Available online: https: //www.aenor.com/normas-y-libros/buscar-libros/detalle?c=173e4c95-9180-e911-a84e-000d3a2fe6cc (accessed on 19 April 2020).

7. ISO 9001:2015 Quality Management Systems—Requirements. Available online: www.aenor.com/normas-ylibros/buscador-de-normas/UNE?c=N0055469 (accessed on 19 April 2020).

8. SEVESO Directive 2012/18/EU of the European Parliament and of the Council of 4 July 2012 on the Control of Major-Accident Hazards Involving Dangerous Substances, Amending and Subsequently Repealing Council Directive 96/82/EC. Available online: https:/eur-lex.europa.eu/eli/dir/2012/18/oj (accessed on 20 April 2020).

9. UNE-ISO 31000:2018. Risk Management. Guidelines. Available online: https://www.une.org/encuentra-tunorma/busca-tu-norma/norma?c=N0059900 (accessed on 21 April 2020).

10. UNE-EN 31010:2011. Risk Management-Risk Assessment Techniques. Available online: https://www.une. org/encuentra-tu-norma/busca-tu-norma/norma?c=N0047287 (accessed on 21 April 2020).

11. Council Directive 89/391/EEC of 12 June 1989 on the Introduction of Measures to Encourage Improvements in the Safety and Health of Workers at work. Available online: https://eur-lex.europa.eu/eli/dir/1989/391/oj (accessed on 20 April 2020).

12. Regulation (EC) No 1907/2006 of the European Parliament and of the Council of 18 December 2006 concerning the Registration, Evaluation, Authorisation and Restriction of Chemicals (REACH), Establishing a European Chemicals Agency. Available online: www.echa.europa.eu/ (accessed on 20 April 2020).

13. Spain. Law 31/1995, November 8th, "Prevención de Riesgos Laborales, y sus Modificaciones"; «BOE» n. 269, 10/11/1995; Boletín Oficial del Estado: Madrid, Spain, 1995; pp. 32590-32611.

14. Spain. Law 54/2003, December 12th, "Reforma del Marco Normativo de la Prevención de Riesgos Laborales"; «BOE» n. 298, 13/12/2003; Boletín Oficial del Estado: Madrid, Spain, 2003; pp. 44408-44415.

15. Spain. Royal Legislative Decree (RD) 486/1997, April 14th, “Disposiciones Minimas de Seguridad y Salud en los Lugares de Trabajo"; «BOE» n. 97, 23/04/1997; Boletín Oficial del Estado: Madrid, Spain, 1997.

16. Spain. Royal Legislative Decree (RD) 1627/1997, October 24th, "Disposiciones Mínimas de Seguridad y de Salud en las Obras de Construcción"; «BOE» n. 256, 25/10/1997; Boletín Oficial del Estado: Madrid, Spain, 1997; pp. 30875-30886.

17. Spain. Law 32/2006, October 18th, "Reguladora de la Subcontratación en el Sector de la Construcción"; «BOE» n. 250, 19/10/2006; Boletín Oficial del Estado: Madrid, Spain, 2006.

18. Spain. Royal Legislative Decree (RD) 171/2004, January 30th, "Desarrollo del Artículo 24 de la Ley 31/1995, de 8 de Noviembre, de Prevención de Riesgos Laborales, en Materia de Coordinación de Actividades Empresariales"; «BOE» $\mathrm{n}$. 27, 31/01/2004; Boletín Oficial del Estado: Madrid, Spain, 2004.

19. Spain. Technical Document of "Instituto Nacional de Seguridad e Higiene en el trabajo" (INSHT) "Evaluación de Riesgos Laborales". Available online: https://www.insst.es/documents/94886/96076/Evaluacion_riesgos. pdf/1371c8cb-7321-48c0-880b-611f6f380c1d (accessed on 22 April 2020).

20. Brzezinska, D.; Bryant, P.; Markowski, A. An Alternative Evaluation and Indicating Methodology for Sustainable Fire Safety in the Process Industry. Sustainability 2019, 11, 4693. [CrossRef]

21. Marhavilas, P.K.; Koulouriotis, D.; Gemeni, V. Risk analysis and assessment methodologies in the work sites: On a review, classification and comparative study of the scientific literature of the period 2000-2009. J. Loss Prev. Process Ind. 2011, 24, 477-523. [CrossRef]

22. Marhavilas, P.K.; Filippidis, M.; Koulinas, G.K.; Koulouriotis, D.E. An expanded HAZOP-study with fuzzy-AHP (XPA-HAZOP technique): Application in a sour crude-oil processing plant. Saf. Sci. 2020, 124, 104590. [CrossRef] 
23. Ilbahar, E.; Karaşan, A.; Cebi, S.; Kahraman, C. A novel approach to risk assessment for occupational health and safety using Pythagorean fuzzy AHP \& fuzzy inference system. Saf. Sci. 2018, 103, 124-136.

24. Sanchez Lite, A.; Brocal Fernández, F.; González Gaya, C.; Fuentes Bargues, J.L.; Sebastián Pérez, M.A. Expert Systems for Assessment of Risks: Exposure to Hand-Arm Vibrations, a Fuzzy Logic Application for Emerging Risks Assessment. In Proceedings of the 22nd International Conference on Project Management and Engineering, Madrid, Spain, 11-13 July 2018.

(C) 2020 by the authors. Licensee MDPI, Basel, Switzerland. This article is an open access article distributed under the terms and conditions of the Creative Commons Attribution (CC BY) license (http://creativecommons.org/licenses/by/4.0/). 